\title{
Cine y publicidad. La intertextualidad en las campañas de Volkswägen
}

\section{Cinema and advertising. Intertextuality in Volkswägen campaings}

\author{
GLORIA JimÉnEZ MARÍN \\ Universidad de Sevilla \\ gloria_jimenez@us.es \\ RODRIGO ElÍAS ZAMBRANO \\ Universidad de Huelva. \\ eliaszambrano@yahoo.es
}

Recibido: 1 de febrero de 2012

Aprobado: 29 del septiembre de 2012

\section{Resumen}

Este artículo es una reflexión sobre la influencia del cine en la publicidad comercial, concretamente se centra en un caso en particular: se trata de la serie de anuncios que componen la campaña La Guerra de las Galaxias de la marca de automoción alemana Volkswägen, en las que se encuentran nexos con la saga dirigida por George Lucas. El objetivo del siguiente pretende, mediante un análisis de discurso reflexivo, evidenciar que realmente existe dicha intertextualidad. Los protagonistas, la música, los temas, el eslogan... son algunas de las claves que apuntan hasta este vínculo intencionado por parte de la casa Audi-Volkswägen.

Palabras clave: automóviles, cine, discurso, intertextualidad, publicidad, semiótica.

Jiménez Marín, G. Elías Zambrano, R. (2013): Cine y publicidad. La intertextualidad en las campañas de Volkswägen. Arte, Individuo y Sociedad, 25(1) 153-167
Abstract
This article is a reflexion about cinema's influence on commercial advertising, specifically the cine- ma on spots. And much timely, the research will be based on a particular case: this is the series of ads of Germany's campaign based on Star Wars, for the Volkswägen brand, which include nexus to the saga directed by George Lucas. The main objective, then, is to prove, through the analysis of the discourse, that the above-mentioned intertextuality exists. Main characters, music, matters and slogan... are some of the keys that show that there is really a deliberate connection made by the creators of the spot.
Key Words: advertising, cars, discourse, film, intertextuality, semiothic.
Jiménez Marín, G. Elías Zambrano, R. (2013): Cinema and advertising. Intertextuality in Volkswägen campaings. Arte, Individuo y Sociedad, 25(1) 153-167
Sumario: 1. Introducción, 2. Intertextualidad, 2.1. Acercamiento al concepto, 2.2 ¿Qué se busca con la 
intertextualidad?, 3. Películas dentro de películas publicitarias: Las relaciones entre cine y publicidad., 4. La campaña de Volkswägen, 4.1. La publicidad de automóviles, 4.2. Volkswägen, por G. Lucas, 4.2.1. Los protagonistas, 4.2.2. Las escenas y situaciones, 4.2.3. La música, 4.2.4. El eslogan, 5. Conclusiones. Referencias.

\section{Introducción}

En su libro El cine, ¿puede hacernos mejores?, Cavell (2003) reflexiona acerca de cómo el cine contribuye a la comprensión, a la empatía o incluso al incremento de la cultura y conocimientos... Y lo cierto es que el cine, indudablemente, además de suponer una fuente de entretenimiento supone, cuanto menos, una herramienta para dar a conocer hechos, historias, etc. y hacer pensar, en multitud de ocasiones, al espectador.

Afirmaba Alain Bergala que

"hacer un filme es superponer tres operaciones: pensar, rodar, montar. Escribir sobre cine necesita de la reflexión, de la mirada, es un trabajo que ha de ser siempre creativo, es crear una película, es abrazarla al principio como un objeto extraño, a veces siempre son extraños, pero, al final, son una extensión de nuestro cuerpo" (en Arias, 2008).

Las relaciones entre el cine, como disciplina, y otras tantas diversas materias o estudios se remontan a los primeros tiempos del séptimo arte: 'Cine e Historia', 'Cine y Sociedad', 'Cine y Educación' son idilios tan antiguos como la propia cinematografía... Así, Fernández ya apuntaba en 1989 que el hecho de instalar argumentos diegéticos en escenarios remotos suponen para director y guionista la posibilidad de emitir y lanzar reflexiones y/o enseñanzas relacionadas con un momento histórico pero con un matiz más ejemplarizante que el que podrían tener en la propia realidad. Esto se debe, fundamentalmente, al hecho de ubicarlas en un escenario histórico distinto a lo que sucede en el momento actual. También Ibars y López (2006: 3) remontan esta relación a los orígenes del cine al expresar que "las razones para esa temprana y fecunda relación son varias. (...) La naturaleza del cine como espectáculo hizo que los cineastas buscaran escenarios exóticos y alejados en el tiempo como una forma más de atraer a los espectadores a las salas de exhibición". También autores como González (1996, p. 29) ya apuntaban que "el discurso cinematográfico representa una cuna de valores sociales en sí mismo", así como Martínez - Salanova explica que el cine aporta elementos sensibles y que su carácter audiovisual así como su disposición para relatar de una manera diferente y más atractiva a otro tipo de relatos o metodologías hacen que se "agilicen los mecanismos de la percepción" (2002, p.33).

Haciendo una brevísima revisión histórica del cine, podemos apoyar todas estas contribuciones al comprobar cómo muchas de las grandes (y no tanto) obras fílmicas tienen una relación muy intensa con disciplinas a priori ajenas: La revolución rusa de los años 20 mostraba en sus películas los beneficios de la revolución (El acorazado Potemkin, 1925); en los años 30, década de la Gran Depresión, el éxito radicó en la dosis de crítica social de los filmes (Scarface, 1932); en los 40 el cine se consideró 
un instrumento de conocimiento y de comunicación a través, por ejemplo, del Neorrealismo (Roma, ciudad abierta, 1945)... O, si viajamos hasta la segunda década del siglo XXI, incluso podemos resaltar el auge que tiene el cine documental de temática social, tal y como podemos comprobar a la luz de la supervivencia y buena salud del Festival Cinestrat (festival de cine documental nacido en el año 2007 y que ha contado ya en 2011 con su V edición).

Cierto es que la relación entre el cine y otras materias es amplia y viene de lejos... pero no por ello se detiene ni deja de evolucionar. En este texto planteamos la relación del cine con la publicidad o, expresado de otro modo: el matrimonio (de conveniencia o no) entre el cine y la publicidad. Y, más concretamente un caso especial: Las últimas campañas de Volkswägen y su relación con la saga La Guerra de las Galaxias, de G. Lucas.

\section{Intertextualidad}

Las distintas manifestaciones artísticas realizadas desde los orígenes del hombre hasta nuestros días han supuesto (y suponen) retos a la investigación, puesto que "al auge de sus expresiones, se suma la compleja continuidad de un simbolismo cuya percepción se nos escapa en gran medida" (Lloyd, 1979: 27) y cuya intertextualidad con otros discursos es evidente (Marcos, 1976). Porque el discurso publicitario se encuentra contaminado, de manera consciente e intencionada, por otros discursos muy distintos y dispares: científico, periodístico, técnico, literario, artístico, etc.

Desde los inicios del discurso publicitario, con las aportaciones que le hicieron ciencias como la psicología o la sociología, se ha venido desarrollando un "paradigma semiótico" (Barthes, 1970: 54), que tiene en cuenta que el contenido del discurso publicitario depende no sólo de los contextos que lo rodean sino de los discursos que lo inspiran y, de este modo, le influyen. Así, el discurso publicitario recurre a menudo al préstamo e imitación del arte en cualquiera de sus formas, incluido el cine, y estableciendo así relaciones transtextuales con las propias obras.

De una manera más o menos sencilla podríamos partir del concepto de intertextualidad como la relación que todo texto, literario o no, contrae con otros textos, estableciendo así su significado. Sin embargo Allen (2006: 2) advierte que

"one of the central ideas in contemporary literary theory, is not a transparant term andso, despite its confident utilization by many theorists and critics, cannot be evoked in an uncomplicatedmanner. Such a term is in danger of meaning nothing more than whatever each particular critic wishes itto mean".

Partiendo de esta idea, nos valdremos de la teoría del estructuralista de Gérard Genette (1989), quien no habla de intertextualidad sino de transtextualidad, como una versión concreta de intertextualidad. Según esta interpretación, la transtextualidad es la transcendencia textual del texto, todo lo que pone el texto en relación con otros textos, de manera evidente o no. Toma, pues, el término transtextualidad, para cubrir todas las manifestaciones de este fenómeno, dividiéndolo en cinco categorías más específicas:

- Intertextualidad: relación de copresencia entre dos o varios textos, así como 
la presencia efectiva de un texto en otro texto: Decitación, plagio o alusión.

- Paratexualidad: El paratexto marca los elementos que ayudan a dirigir y controlar la recepción de un texto por sus lectores. Forma un umbral entre texto y no-texto que consiste en un peritexto (título, título de capítulo, prefacio, notas) y un epitexto (entrevistas, publicidades, reseñas de críticos... y otras discusiones que se encuentran fuera del texto en cuestión).

- Hipertextualidad: Incluye toda relación que une un texto $\mathrm{B}$, el hipertexto, a un texto anterior A, llamado el hipotexto, en el que B estriba sin ser un comentario de A. (es lo que, la mayoría de autores, llama intertexto: un texto que es una fuente importante de significado para otro texto).

- Metatextualidad: Cuando un texto mantiene una relación de comentario con respecto a otro texto, es decir, el texto habla de otro sin citarlo o mencionarlo necesariamente.

- Architextualidad: El carácter architextual de un texto incluye expectaciones genéricas, modales, temáticas y figurativas, refiriéndose a la imitación de modelos genéricos, de tipos de discurso, de modos de enunciación, etc.

En relación a lo que expresa Genette (1989), podemos atribuir a la publicidad las finalidades básicas de las relaciones transtextuales, considerando que, por un lado, se basan en una búsqueda de autoridad para intentar dar por medio de la voz, la figura, la obra de otro, un determinado prestigio, sabiduría, reconocimiento, etc.; y por otro lado, esta introducción produce un efecto de complicidad o de reconocimiento en el público objetivo.

Estudios realizados con anterioridad (Alonso y Conde, 1994; Eguizábal, 1990) insisten en que esta trasgresión del código empleado por la publicidad no es aleatoria, sino que responde a la exigencia de expresar un mismo efecto, un fin determinado, de manera diferente. También autores como Berger (1991) definen esta intertextualidad como el uso consciente o inconsciente del material de otros en un texto. O'Donohoe $(1997,2000)$ desarrolla más el concepto y lo ubica en el tiempo; plantea que se trata de un fenómeno postmoderno y analiza sus implicaciones en la percepción de los mensajes publicitarios.

$\mathrm{Y}$ es que la intertextualidad entre varios códigos es una evidencia a la que acude el discurso publicitario para poner de manifiesto la frecuente evolución e innovación que su carácter mercantil le niega, ya que su fin y objetivo no es la experiencia estética del receptor, sino la consolidación de una ideología consumista: el fin pasa por la compra o consumo del producto que se anuncia. Es más, autores como Wernick (1991) sugieren y afirman que los anuncios, más que otro tipo de discursos, no se construyen de forma independiente, sino acudiendo a otro tipo de manifestaciones. Es aquí donde nos centramos: en esta construcción del discurso publicitario a partir del cine. 


\subsection{Acercamiento al concepto}

El concepto de intertextualidad como lo entiende la profesora López Mora en su artículo "La publicidad como característica esencial del lenguaje publicitario" (2007) es

"la relación de dependencia de todo discurso con otros discursos o géneros discursivos, se muestra como una de las principales características de la publicidad entendida como género semiótico, como lenguaje complejo en el que se pone en juego cualquier medio de expresión existente. El publicitario es un género que imita, homenajea, parodia, sintetiza todos los lenguajes conocidos".

Sin embargo, hay que retroceder en el tiempo hasta el término acuñado por Julia Kristeva a partir de la lectura de la obra de Batjín que se puede encontrar en su obra Semiótica (1978) para entender lo que se entiende por influencias. Autores como Batjín, Barthes o Genette abordaron previamente este fenómeno que arranca en la literatura para saltar posteriormente a otros campos. La intertextualidad que define Kristeva, y que retrata López en su artículo (2007), tiene además diferentes niveles o grados de alusión. Esta diferencia someramente entre cita literal, alusión leve, homenaje a una película o un género cinematográfico o la utilización velada o manifiesta de otros discursos. En definitiva: imitación, influencia y copia en la que juega un papel muy importante el saber enciclopédico del receptor al que en definitiva se trata de enganchar con un argumento de contenido cultural.

A partir de este punto se podría afirmar que muchos spots publicitarios beben de otras fuentes y que más allá de la finalidad comercial, los autores -directores y/o agencias- encuentran en el arte (y en el séptimo, más concretamente) una fuente de inspiración y que supone una producción simbólica para crear pequeñas obras de arte.

La relación cine-publicidad también está escenificada, tal y como expresa Marroquín (2010) en directores como Pedro Almodóvar, Julio Medem, Isabel Coixet, Víctor Erice, Martin Scorsese o Alfred Hitchcock entre un largo etcétera. Y es que:

"el hecho de que un gran número de realizadores de cine hayan incursionado en la publicidad nos enseña que es un campo que hay que tomar en serio y cuyo desarrollo merece ser observado y analizado"

apunta Meier en su artículo "Cine y spot publicitario" (2009), aunque en este caso se trata de una relación que viene de vuelta, desde el cine y hasta el discurso publicitario, en multitud de ocasiones plagado de referencias al propio discurso en el que estos directores están acostumbrados a trabajar. Un círculo cerrado que llega a su máximo esplendor cuando la publicidad se fija en el cine y recorta un fragmento, un fotograma o un ambiente.

En este sentido, De Felipe (2006) apunta, en su artículo "La sombra de una de(u) da: publicitarios y cineastas", que casi siempre estos directores dan el salto de la publicidad al cine y son los menos los que lo hacen al contrario o desandan el camino (aunque tenemos casos recientes: Álex de la Iglesia su campaña para la FAD o Bigas Luna para sus anuncios de KH7). 
En esta línea se expresa Segarra (2001: 63), quien señala que la intertextualidad: "es una técnica parásita, aprovecha para su beneficio el talento de otros, reutiliza hallazgos, vampiriza ideas. No deja de ser lógico. En nuestro afán por conectar con el consumidor resulta más seguro, y también más cómodo, aprovecharnos de aquello que ya ha alcanzado el alma de nuestro público".

El retorno se produce cuando la publicidad, incluso en las ocasiones en las que persigue finalmente una meta económica, cumple un papel en la sociedad: en este caso de altavoz de los símbolos que definen a esa misma sociedad.

Un retorno que abre el círculo al que nos referíamos. Y es que, en palabras de Rodríguez (2003: 5):

"el intertexto no sólo se nutre del texto que está en su origen, sino que lo nutre retroactivamente, y quizá ya no nos sea posible entender a Homero sin recurrir a Joyce, contemplar la Gioconda sin superponerle esos bigotes subversivos de Duchamp -o sobre ellos los de Dalí-, (...)".

La publicidad se apoya en el séptimo arte para buscar un universo común entre el espectador y el creador del mensaje.

En este punto, y tras la reflexión de algunos autores, cabe hacerse una pregunta: ¿es menos creativo un anuncio que se nutre de algo ya inventado como puede ser una escena de un largometraje o un género? En este sentido, cabe anotar la definición que da del término 'innovación' la Real Academia Española en su segunda acepción (2001: 452): "creación o modificación de un producto, y su introducción en un mercado", es decir, se puede innovar introduciendo una modificación en algo que ya existe. De este modo, el autor lo que hace es aplicar una idea existente a su producto.

Para Jorge Maranhão (1988: 35) "todas las principales marcas de productos de nuestra organización social capitalista más allá de sus funciones y utilizar su valores de cambio, son considerados genios porque tocan el fenómeno del arte". Así, se puede observar que esta conexión da al espectador cierto placer. Se trata de un lenguaje conocido que no supone un esfuerzo excesivo pero sí el suficiente como para comprobar que él mismo ha cerrado un círculo al que le falta un tramo. Ahora, todo encaja. Este producto se puede diferenciar del resto por sus cualidades pero también por pertenecer activamente al entorno sociocultural que nos rodea.

\section{2. ¿Qué se busca con la intertextualidad?}

Sin olvidar que el tema de la intertextualidad en publicidad, sean cuales sean las otras disciplinas que la atraviesan tangencialmente, ha sido tratado en numerosas ocasiones por expertos en la materia para mostrar al mundo un guiño estético y/o incluso transmitir emociones e ideas, se busca en este artículo una lectura amena por parte del lector para mostrar (y evidenciar) esa relación entre el spot de Volkswägen y la saga La Guerra de las Galaxias, dirigida por G. Asimismo, se trata de averiguar cuáles son las pretensiones de los creadores del spot: qué quiere transmitir la casa Volkswägen - Audi con este anuncio más de veinte años después de que se estrenara la saga original a la que alude (no nos referimos a La amenaza fantasma, El ataque 
de los clones o La guerra de los Sith): La Guerra de las Galaxias, El retorno del Jedi y El imperio contrataca. Cabe preguntarse si es eficaz este tipo de comunicación en la que se ensarta otro texto para alcanzar un carácter simbólico que llegue hasta el público y consiga el efecto deseado.

Para abordar el tema primero se conduciremos al lector por un recorrido a través de un marco teórico que sitúa el concepto de la 'intertextualidad', también entendida interdiscursividad (Allen, 2006) -como una evolución del término y su introducción en otras disciplinas- para entender la finalidad persuasiva que persigue todo acto de creación publicitaria.

\section{Películas dentro de películas publicitarias: Las relaciones entre cine y publicidad}

Los símbolos, las marcas o los pequeños objetos fetiches de la vida cotidiana pretenden empatizar con nuestro 'yo'. Los publicitarios lo saben y buscan en el imaginario colectivo aquello que más se pueda identificar con el de nuestro público, explotando al máximo el mundo de las sensaciones.

$\mathrm{Y}$ es que "todo aquello que moviliza las emociones es una pista segura para captar la atención: el cine, el fútbol, la música. La red de conexiones puede ser infinita..." (López, 2007:48), por ello, los creativos están abiertos siempre a nuevas ideas pero no dejan de reconocer que la cultura, y concretamente, el cine, es una fábrica de sueños. ¿Quién no se olvidado del resto del mundo atrapado por el poder de la combinación de imágenes en movimiento, música y palabras? En este sentido, también el papel de la publicidad no es otro que el de persuadir-además de informar- o encandilar, si se prefiere. Y al igual que el cine, los spots no sólo lo son en su forma (estética, planos, montaje...), sino también en su contenido. Numerosos spots están atravesados por mil referencias, perceptibles o no, al séptimo arte, ya sea por una película en concreto, por una temática, un género cinematográfico, un personaje o un director. Pura simbiosis.

Jover (2007: 100) comenta en este sentido:

"Respecto a las influencias del séptimo arte en la publicidad, éstas son de sobra conocidas, acusándose cada vez más sus efectos tanto estéticos como referenciales. En multitud de anuncios se utilizan alusiones icónicas, verbales y musicales sobre películas, personajes o actores que forman parte del imaginario colectivo, mientras que en otros se recurre a cuestiones estéticas que apelan directamente al film: color, puesta en escena, iluminación”.

Así, películas como Amélie (2001) de Jean Pierre Jeunet o Sin city (2005) de Frank Miller han sido claramente evocadoras de anuncios tales como el de la Agencia Tributaria en 2002 o La llamada del ron Cacique, respectivamente. En el primero, Jover Oliver, apunta una similitud en los colores: vivos y saturados además del parecido de las actrices en ambos textos- mientras que en el caso de Sin City y "La llamada" se trata de una alusión a la estética del cómic (López Mora, 2007). Por otra parte, ambas cintas nos sirven para retratar cómo la intertextualidad salta de un apartado a otro, pues en este caso además han inspirado 
la estética del videojuego para Play Station 3, The Sabotear (Anónimo, 2010a).

El reciente caso de la saga Crepúsculo es otro buen ejemplo de cómo una película tan comercial puede seducir a un target adolescente. Los spot de bollería "Qé muerdes" y la campaña "Deja que los vampiros se mueran de hambre" de la Federación Española de Donantes de Sangre son referencias claras a la película (basada a su vez en los libros de Stephenie Meyer) que ha hecho furor en todo el mundo.

También, de manera más reciente, encontramos el caso de All Bran en el que se existen fuertes referencias a la película El diablo viste de Prada.

\section{La publicidad de automóviles}

Centrándonos ya en los spots exclusivamente de automóviles, hay que destacar que durante los últimos años hemos venido presenciando una evolución en los mismos, como en otros campos se ha ido andando hacia la publicidad emocional. En muchos casos, el objeto de compra, en este caso automóviles de gama alta, tienen unas características muy parecidas. De ahí que se explote el lado emocional y se apueste por la marca por encima de otras características del producto.

Se ha apuntado anteriormente que el saber enciclopédico del receptor juega un papel crucial en este juego de recordar la película en cuestión. Por eso, se puede afirmar que los spots son en muchos casos auténticos remakes de las escenas más conocidas de una determinada película. Así ocurre, como señala Jover Oliver (2007: 107-109), en el spot de Daewoo Tacuma con la película El Exorcista donde se recrea el momento más famoso de toda la cinta en la que la niña gira completamente la cabeza o el del coche Quattro de la casa Audi en el que el gigantesco mono de King Kong queda embelesado por la rubia (y en esta ocasión aparta a la chica y se queda con el coche).

La comprensión por parte del espectador variará dependiendo de un sinfín de variables que van desde la edad del espectador hasta el conocimiento del film pasando por una buena recreación o giño al original. Un simple encuadre puede poner sobre la pista al receptor, que rodeado por millones de estímulos, reconocerá (o no) una determinada película. En el caso del reconocimiento, la satisfacción será total y creará un vínculo especial con el anuncio. Y es ahí donde el receptor se hace importante: en tanto en cuanto reconoce la fuente, la siente y establece algún tipo de vínculo emocional con el anuncio. Porque, tal y como afirman Ramos, Delgado y Jiménez (2007: 35): "Sentido y sensibilidad van ahora de la mano y no enfrentados. Así, cada vez son más las campañas que utilizan este enfoque - tal es el caso que nos ocupa, el sector del automóvil - consiguiendo influir de manera positiva en la decisión de compra".

\subsection{Estado actual del sector automovilístico}

Si ojeamos cualquier periódico, revista o vemos televisión, rápidamente podremos advertir la presencia de anuncios de automóviles en cualquiera de estos medios. El sector del automóvil se constituye hoy en día como uno de los principales motores de la economía en nuestro país, si bien es cierto que en la actualidad está pasando por una crisis (debido, entre otras, a la crisis económica mundial).

Ello tiene un claro reflejo en el ámbito publicitario, en un doble sentido: por un lado, a pesar del descenso en producción, el sector ha ido aumentando su inversión 
publicitaria hasta el año 2010, en que la recesión se hizo patente. Por otro lado, el automóvil, ha perdido en gran parte su valor tangible para convertirse en objeto de deseo cargado de un gran poder simbólico, dejando de ser un mero instrumento de transporte. Ahora, aspectos como el placer de conducir, la independencia y la satisfacción son valores que han convertido al vehículo en un producto mucho más emocional Por tanto, tenemos ante nosotros un sector que apuesta cada vez más por la publicidad y, ante la diversidad de marcas, debe diferenciarse a través de la comunicación. En este sentido es donde se observa cómo la tendencia actual lleva a utilizar el lado emocional como eje creativo. Así, según el estudio Driving in Europe 1010/11, publicado por Motorpress-Ibérica (Cfr. Control, 2011), donde se analiza la situación de la industria del automóvil en Europa, el componente emocional es una de las razones de mayor peso en la decisión de los consumidores a la hora de adquirir un vehículo.

Ello no quiere decir que los aspectos denotativos estén olvidados, si bien la tendencia natural es que los aspectos racionales sean comunicados a través del marketing directo o promocional mientras que para los medios masivos se realiza una comunicación mucho más emocional.

Así lo señala Lozano, Director de Cuentas de DDB Barcelona, agencia responsable de la publicidad de Volkswagen y Audi en los últimos años. El publicitario afirma:

"La publicidad tradicional (en referencia a la emitida en televisión) es clave ya que es la manera que tiene la marca de comunicarse con sus potenciales clientes a nivel masivo. Es la oportunidad de transmitir no solamente los beneficios del producto sino su filosofia de empresa, lo que permite posicionar o dotar de personalidad un producto o una marca en el mercado de la manera más rápida y eficiente" (Control, 73: 93).

Llegamos entonces a un punto, en el que los mensajes publicitarios de automóviles están reflejando esa tendencia clave, encontrándonos con muchos anuncios que reflejan una situación de pura enunciación, donde el objeto a publicitar prácticamente se omite, por lo que no hay anuncio, sólo enunciado. Estaríamos entonces ante esa publicidad estructural de la que nos hablaba Caro capaz de "conferir una significación virtual (no materializable) a la marca, que ocupa el lugar que antes le correspondía al producto" (1994: 120). Este tipo de publicidad, poseedora de un gran poder de seducción, ha sido elegida en los últimos años por múltiples marcas del sector; ahí tenemos por ejemplo el caso de mano de BMW, Amnesia de Golf o Cosas de Audi.

No obstante, comenzábamos esta investigación planteando que la clásica dicotomía cartesiana que divide razón y emoción, está siendo superada por un enfoque que une ambos componentes, en vez de separarlos. Y ello, se está viendo reflejado en la comunicación publicitaria. Así lo afirma Muñiz que encuentra que las dos vías -razón y emoción- siempre se han utilizado como forma de persuasión, pero como dos caminos separados (2005: 121). Es lo que Zaltman (2004: 57) ha dado en llamar acertadamente la "Tiranía del 'o", es decir o íbamos por un camino o por otro. No obstante el autor plantea ese enfoque integrador que aúna ambas vertientes uniendo ambos caminos en vez de bifurcarlos. En la misma línea hace años que trabaja Damasio, que en su obra El error de Descartes (1994) investiga cómo el pensamiento racional y el sentimiento se unen en el ser humano desde una base neurológica. 
La publicidad de automóviles ha entendido que tiene que romper esa línea divisoria para unir por fin ambos polos. Sentido y sensibilidad van ahora de la mano y no enfrentados. Así, cada vez son más las campañas que utilizan este enfoque (tal es el caso que nos ocupa, el sector del automóvil) consiguiendo influir de manera positiva en la decisión de compra.

\subsection{Volkswägen, por G. Lucas}

Razón y emoción de la mano de un Volkswägen, en clave George Lucas. O, expresado de otro modo, las últimas campañas de Volkswagën son un fiel reflejo o versión de la saga de La Guerra de las Galaxias, en cualquiera de sus partes.

En 2011 Volkswagen presentó para su campaña una versión mínima e irónica de uno de los personajes de la famosa historia: Darth Vader, pero en miniatura. Es decir, un niño de unos 8-10 años disfrazado de uno de los protagonistas de la historia intergaláctica.

El spot, titulado originalmente The Force ${ }^{l}$, alude al ente superior citado en la película. El mencionado spot publicitario está protagonizado por un niño, disfrazado de Darth Vader (muy parecido a Luke Skywalker) y por el padre de Luke Skywalker en La Guerra de las Galaxias, que trata de utilizar el poder de la Fuerza ${ }^{2}$ en distintos objetos que tienen en su casa: la bicicleta estática, el perro, la lavadora, un muñeco...Sus poderes no funcionan hasta que se acerca al coche, el nuevo modelo de Volkswagen, el Passat (que su padre, con un control remoto hace que encienda las luces mientras guiña un ojo a su esposa).

La campaña llegó directo al corazón de los baby boomers, las madres y los jóvenes que buscan alta tecnología así como confort en un automóvil. Todo un acontecimiento según expertos en el campo de la publicidad, según marketingdirecto.com. Y, tal fue el éxito, que incluso Greenpeace hizo su contracampaña, titulada El lado oscuro para denunciar la negativa política medioambiental de la compañía alemana.

Y esa campaña, que causó sensación, trae su continuación.

2012. Nueva versión de la clásica Marcha Imperial, interpretada por perros, es decir, ladrada por un coro de once caninos que además de promocionar la marca de automóviles, rinden un pequeño homenaje a La Guerra de las Galaxias, que a partir de 2012 comienza a exhibirse en 3D.

The Bark Side ${ }^{3}$ es el nombre del spot que la marca alemana ha empezado ya a emitir en determinados canales (entre ellos, el propio canal de Youtube) y cuya contratación está ya cerrada para la próxima edición de la Super Bowl.

La agencia responsable es Deutsch LA, que tal como lo hizo con la campaña de 2011, subió a internet un teaser del anuncio unos días antes de la final de la liga de futbol americano.

A fecha de enero de 2012, las visitas al teaser ya superan los siete millones de personas. 


\subsubsection{Los protagonistas}

En la campaña La Fuerza aparece el personaje de Darth Vader, el antagonista principal de la trilogía original de la saga La Guerra de las Galaxias que aparece en los episodios IV, V y VI, así como en el III a través de la transformación de Anakin Skywalker en este oscuro personaje.

La trilogía original representa al personaje como un discípulo del emperador (Darth Sidious), quien emprende una guerra en la galaxia contra los activistas de la Alianza Rebelde. Sin embargo, y haciendo una revisión a la precuela, el personaje es realmente un niño, Anakin Skywalker, un Caballero Jedi antes de convertirse en el representante del lado oscuro de la Fuerza.

Pese a que las respectivas son parecidas pero no idénticas, podemos señalar que en su misma oposición encontramos un juego donde ambas unidades giran en torno a un personaje masculino, niño y adulto a la vez: En el spot La Fuerza intuimos que el protagonista es ese niño, ese Anakin Skywalder que juega a ser Darth Vader, de modo que se unen en el mismo personaje de la campaña los dos personajes de la saga fílmica.

\subsubsection{Las escenas y situaciones}

Al personaje protagonista se suman otra serie de situaciones que ayudan a comprender el guiño de los creativos del spot hacia La Guerra de las Galaxias. Uno de los escenarios principales de la película es la nave donde se narran las acciones de Darth Vader. Dicha nave es representada con formas y colores similares a la perspectiva del vehículo que se anuncia: en el anuncio aparece el modelo de Passat cual nave nodriza.

Curiosamente ambos son los poderosos que todo lo pueden en su ámbito de poder, la galaxia en el caso de La Guerra de las Galaxias, y el hogar-jardín en el caso de La Fuerza. Ambos consiguen lo que se proponen con tan solo un juego de manos... Y, evidentemente, ambos visten de igual modo.

Cuando en el spot La Fuerza el símil de Darth Vader no consigue su propósito, aparece de manera sigilosa su padre, realizando tal fin gracias a un mando a distancia... Pese al fraude evidente, al final ambos consiguen sus propósitos...

Hacer de poderosos y conseguir sus objetivos quedan plasmados en anuncio y película; vemos, de este modo, cómo la temática retocada de la película enlaza con la promesa del Volkswägen Passat.

\subsubsection{La música}

Brevemente podemos apuntar que en ambas obras (anuncio y saga) se usa la llamada Marcha Imperial, el segundo tema más conocido y célebre de toda la saga. Con un retumbante sonido de inspiración militar representa los sentimientos de crueldad y dureza, representa el rigor imperial, así como la atemorizante presencia del caballero oscuro Darth Vader.

Compuesta para El Imperio Contraataca y para El Retorno del Jedi, en la precuela (episodios I, II y III), se oye una versión minimalista... Y conforme la conversión 
de Anakin Skywalker se acerca al personaje de Darth Vader, se utilizar con más frecuencia... Es justo esta versión minimalista, menos dura que la usada en los tres episodios originales (IV, V y VI), la que se emplea para la campaña La Fuerza. Quizás por darle un sentido algo más infantil, tierno o incluso paternal (recordemos que los actores del anuncio son un niño y su padre).

En el segundo de los anuncios, en The Bark Side es incluso más minimalista: la marcha imperial se limita a ser interpretada con ladridos de perros.

\subsubsection{El eslogan}

"Coming soon" es el eslogan de esa campaña concreta, haciendo un símil con un tráiler cinematográfico. Con las mismas palabras usadas en cualquier estreno de cine, en cualquier campaña de promoción de un producto cinematográfico. Solo que en este caso el producto es un vehículo.

\section{Conclusiones}

Tras un análisis de elementos como personajes, escenarios, música... podemos afirmar y detectar con seguridad la relación de intertexualidad que encontramos entre dos discursos, el publicitario y el cinematográfico, y que podemos aplicar a un caso concreto: Las campañas La Fuerza y The Bark Side, de la alemana Volkswägen y La Guerra de las Galaxias, de George Lucas.

La relación entre el arte y la publicidad no es inédita ni pensamos que vaya a extinguirse en breve. Y es que este tipo de relaciones, cuanto menos, fomenta unas conexiones mentales en el público que es capaz de recordar y asociar el film original con la idea plasmada con finalidad comercial y/o persuasiva, tal y como observamos en estudios como los de Sánchez (1999) o Ruiz-Vargas (1998). Porque en el fondo (y a veces en la superficie) todo texto es intertexto.

Hasta qué punto esas conexiones pueden ayudar a conseguir los objetivos planteados con la campaña publicitaria es motivo de un futuro estudio y análisis mucho mayor en cantidad y c(u)alidad ${ }^{4}$. Pero lo que sí nos encontramos en disposición de afirmar es que, al margen de los niveles de eficacia publicitaria, no podemos despreciar esta forma de hacer publicidad, esta forma de relacionar ambos discursos.

De cualquier modo, aún sin ser la única manera de expresar la intertextualidad a nivel publicitario, sí es cierto que, bien empleada y bien orientada hacia su adecuado target, estos intertextos pueden dar lugar a muchos aspectos positivos y beneficiosos en la campaña y, por ende, en los objetivos planteados y, sobre todo, la estrategia que la empresa sigue. 


\section{Referencias}

A.A.V.V. (2001). Diccionario de la lengua española. Madrid: Real Academia de la Lengua Española.

Allen, G. (2006). Intertextuality. Londres: Routledge

Arias Carrión, R. (2008). El cine como espejo social. Ejercicio de análisis cinematográfico relacionado con las ciencias sociales. Madrid, Tasa Ediciones.

Baños González, M. y Rodríguez García, T. (2005). Al filo de la verdad. Historias de la publicidad en el cine. Madrid: Dossat.

Caro, A. (1994). La publicidad que vivimos. Madrid: Ed. Eresma \& Celeste.

Cavell, S. (2003). El cine, ¿puede hacernos mejores? Katz Editores: Buenos Aires.

Checa Godoy, Antonio (2007). Historia de la Publicidad. La Coruña: Netbiblo.

Damasio, A. (1994). El error de Descartes. Barcelona, Crítica.

De Felipe, F. (2006). La sombra de una de(u)da. En Trípodos no 18, pp. 95-108.

Espelt, R. (2001). Jonás cumplió los 25. La educación formal en el cine de ficción 1975-2000. Barcelona, Alertes, .

Fernández Sebastián, J. (1989): Cine e Historia en el aula. Madrid: Akal.

García de Lucas, v., Rodríguez Merchán, e. \& Sales Heredia, J. (2006). Cine entre líneas. Periodistas en la pantalla. Valladolid, SICV,

González-Martel, J.(1996). El cine en el universo de la ética. El cine-fórum. Madrid, Anaya, IBARS FERNÁNDEZ, R. y LÓPEZ SORIANO, I.: "La historia y el cine" en CLIO, n. ${ }^{\circ}$ 32, Madrid, Mc, 2006.

Informe UNESCO: Declaración sobre la Educación de los Medios, 1982.

Jover, R. (2007). El cine en la publicidad de automóviles. En Perales, F. (ed.). Cine y publicidad. Madrid: Fragua Editorial, pp. 99-121.

Kristeva, J. (1978). Semiótica, 2. Madrid: Fundamentos.

Laviana, J. C. (1996).Los chicos de la prensa. Madrid: Níkel Odeón Dos.

López, P. (2007). La intertextualidad como característica esencial del discurso publicitario, en Círculo de Lingüística aplicada a la comunicación (clac) 30, pp. 45-67.

Loscertales y otros (1996). Los estereotipos en el cine: La imagen social del rol docente. En Marín, M. y Medina, F.J. (Comp.), Psicología del desarrollo y de la educación. La intervención psicoeducativa. Sevilla: Eudema.

Maranhão, J. (1988). A arte da publicidade: estética, crítica e kitsch. Sao Paulo: Papirus.

Marín, M., Núñez, T. y Loscertales, F. (2000). Imagen social del profesorado. Un estudio a partir de los medios de Comunicación: prensa y TV. En Revista Interuniversitaria de Formación del Profesorado. n ${ }^{\circ} 39$, pp. 147-156, .

Martín, M. (1978). La mediación social. Madrid: Akal.

Martínez-Salanova, E. (2001). ¿Cómo utilizar el cine para la educación en valores? En el libro Actas del encuentro de grupos de trabajo. pp. 31-54. Málaga: Centro de Profesorado.

Martínez-Salanova, E. (2002). Aprender con el cine, aprender de película. Una visión didáctica para aprender e investigar con el cine. Huelva: Grupo Comunicar.

Muñiz, J. A. (2006). El papel del eslogan en la actitud hacia la marca. En Questiones Publicitarias. $\mathrm{n}^{\circ}$ 10, pp.119-142. 
Muñoz, S. \& Gracia, D. (2006). Médicos en el cine. Dilemas bioéticos: sentimientos, razones y deberes. Madrid: Editorial complutense, .

Perales, F. (2007). Cine y Publicidad. Madrid: Fragua.

Pérez, J. C. (2000). El cuerpo en venta. Relación entre arte y publicidad. Madrid: Cátedra.

Pérez, J.A. \& Pérez, E. (2010). Cien abogados en el cine de ayer y de hoy. Salamanca: Ediciones OR,

Ramos, M; Delgado, T. \& Jiménez, G. (2007). Las nuevas estrategias de comunicación en el sector automovilístico: razón y emoción en la campaña de Audi. En Revista FISEC-Estrategias - Facultad de Ciencias Sociales de la Universidad Nacional de Lomas de Zamora. Año III, Número 6, Mesa VII, pp. 23-45

Rizo, M. (2006). El interaccionismo simbólico y la Escuela de Palo Alto. Hacia un nuevo concepto de comunicación. En Aula Abierta - Lecciones básicas. Barcelona: Portal de la Comunicación Incom, UAB .

Rodríguez, R. \& K. Mora (2002). Frankenstein y el cirujano plástico. Una guía multimedia de semiótica de la publicidad. Alicante: Publicaciones de la Universidad de Alicante.

Rodríguez, R. (2003). Publicidad omnívora, publicidad caníbal: el intertexto polémico. Comunicación presentada en las Jornadas de Publicidade e Comunicação, LabCom, Universidade da Beira Interior, Covilhã, Portugal, pp. 1-15.

Ruiz-vargas, J. M. (1998): Psicología de la memoria. Alianza Editorial, Madrid.

Segarra, T. (2001). ¿Por qué los publicistas llamamos películas a los anuncios?. En Trípodos $\mathrm{n}^{\circ}$ 11, pp. 61-66.

Sánchez, M. J. (1999). Relación entre el recuerdo y la actitud hacia el anuncio publicitario: un análisis empírico. En ESIC Market, Sept.-Dic, pp. 105-126.

Utrera, R. (2002). Cine, arte y artilugios. Sevilla: Padilla Libros Editores \& Libreros.

Zaltman, G. (2004). Cómo piensan los consumidores: lo que nuestros clientes no pueden decirnos y nuestros competidores no saben. Barcelona: Urano.

\section{Referencias web}

Anónimo (2010): "Sin city y Amelie inspiran la estética de The Saboteur", en Última pantalla. [Recuperado en http://www.ultimapantalla.net/2009/05/sin-city-yamelie-inspiran-la-estetica.html] (Consultado el 5/5/2010).

Anónimo (2010b): "Los comienzos", en Mercedes-Benz.es [Recuperado en http:// www.mercedes-benz.es/content/spain/mpc/mpc_spain_website/es/home_mpc/ passengercars/home/passengercars_world/legend_and_history/beginnings.html] (Consultado el 8/1/2011).

Anónimo (2012): "El esperado anuncio de Volkswagen para la Super Bowl aprueba raspado: nada superará 'The Force"" en Marketingdirecto.com. (Consultado el 06/02/2012). Recuperado en http://www.marketingdirecto.com/actualidad/ publicidad/el-esperado-anuncio-de-volkswagen-para-la-super-bowl-apruebaraspado-nada-superara-the-force/] 
Marroquín, A. (2010). I need Spain. Campaña publicitaria 2010. [Recuperado en: http://www.juliomedem.org/filmografia/ineedspain.html] (Consultado el 12 de octubre de 2010)

Meier, A. (2009). Cine y spot publicitario. En El ojo que piensa. [Recuperado en http://www.elojoquepiensa.net/index.php/numeros-anteriores/114] (Consultado el 14.4.2010).

Vega S., Guillermo (24/06/2010): "Mercedes renueva la estrella y retoma el eslogan del fundador", en Cinco días. Recuperado en Internet (14.01.11): http://www. cincodias.com/articulo/empresas/Mercedes-renueva-estrella-retoma-esloganfundador/20100624cdscdiemp_10/

\section{Notas}

1. "La Fuerza", título de la campaña con la que nos referiremos a partir de ahora

2. Con la Fuerza, aquí, nos referimos al poder superior que guía a Darth Vader, no al título del anuncio.

3. The Bark Side es una campaña que solo ha sido emitida en su versión original, en inglés, y por tanto no ha llegado al ámbito latinoamericano (ni España ni América Latina). De ahí que el título no aparezca nunca en castellano.

4. Juego de palabras intencionado: Nos referimos a la calidad de las acciones publicitarias para conseguir los objetivos planteados, así como a las cualidades definidas en las acciones y piezas publicitarias. 